[REVIEW]

\title{
The Syntax of Sentential Stress
}

By Arsalan Kahnemuyipour, Oxford Studies in Theoretical Linguistics 25, Oxford University Press, Oxford, 2009, xiii+196pp.

\author{
YUKO Z. YOSHIDA \\ Doshisha University*
}

Keywords: phase, stress domain, multiple spell-out, syntactic approach, cross-linguistic

\section{Introduction}

This monograph offers an elegant explanation of the sentential stress phenomena found in languages of various word-order types. The core analysis of informationally neutral and informationally non-neutral sentence stress is couched in Minimalism (Chomsky (1995)), or phases and multiple spell-out theory (Chomsky $(2000,2001))$. The author claims that stress assignment applies only to spell-out, in other words, to surface structure, and the property in the 'deeper' structure is not inherited by the spell-out. This monograph contributes to the theory of multiple spell-out and phases proposed in Minimalism by supplying further empirical support, and serves as a refutation to criticism against 'phase' (Boeckx and Grohmann (2007)).

\section{Minimalist Approach to Sentential Stress}

The first chapter serves to illustrate the framework adopted by Kahnemuyipour: the Minimalist Program. This framework is based on phases and multiple spell-out and assumes the Y model of grammar, which disallows purely phonological operations from triggering syntactic operations. The Y model branches towards a spell-out of Logical Form (LF) and Phonological Form (PF), and in the model the two components are not allowed to feed each other directly. Certain aspects of Kayne's antisymmetry

* My gratitude goes to Shanti Ulfsbjorninn, Geoff Williams and anonymous reviewers of English Linguistics for their invaluable comments. Any defects of this paper are of course mine alone. 
(1994) are adopted into Kahnemuyipour's analysis, where Minimalism and antisymmetry are compatible. Kahnemuyipour suggests a weaker version of Cinque's (1999) universal hierarchy (cartographic) system: with the predetermined relative order of elements in various languages, a particular element (he uses an example of a manner adverb) is allowed to have some parametric variation in its behavior.

\section{Setting the Goals: Syntactic vs. Phonological Approaches}

In this monograph, Kahnemuyipour attempts to elucidate some problems of sentential stress assignment for both phonological and syntactic approaches. The monograph itself offers a more restrictive and explanatory syntactic account of the sentential stress issues recapitulated in Chapters 2 and 3.

Chapter 2 highlights the 'overgeneration problem' of phonological approaches in sentences with neutral focus: such as Metrical Grid theory and Phrasal Phonology. Some cross-linguistic variations can be accounted for with these approaches with language specific rules; due to the lack of restrictive force, however, they predict some non-attestable sentence stress patterns. In SOV languages, the approaches above predict a stress on the subject, which is not only unattested in SOV, but in fact does not occur in any language type. Kahnemuyipour also points out the limited access of phonological approaches to more complex syntactic structures such as passive and unaccusative sentences.

The monograph reviews other syntactic approaches to sentential stress in Chapter 3 pointing out some shortcomings of three previous analyses: Zubizarreta (1998) for failing to account for secondary stress, Cinque (1993) for a problem relating to overgeneration, and Legate (2003) for falsely predicting stresses on wh-objects and topicalized objects. The Cinque's (1993) analysis would overextend itself into predicting even the most deeply embedded constituent, and yields a non-contextual unaccusative sentence with stress on the subject. To account for this, information structure had to be incorporated to undermine his null theory of sentential stress. In Chapter 4, Kahnemuyipour provides solutions to these issues, and thus some of the details of each approach introduced above will be outlined accordingly.

\section{Phase-based Analysis of Sentential Stress}

Chapter 4 of this monograph is devoted to demonstrating how a phasebased analysis successfully predicts the location of primary stress, as well 
as secondary stress in a focus-neutral sentence. Bottom-up derivation is assumed, which proceeds phase-by-phase. At each phase, the syntactic complement of the phase head receives phonological interpretation. This syntactic block is termed 'SPELLEE.' The SPELLEE, the complement of the $\mathrm{v}$ head, should contain internal arguments and the inner aspectual heads. Kahnemuyipour's proposal for the Sentence Stress Rule (SS) follows the mechanism of assigning stress: sentential stress is assigned at the phase level to the highest phonologically non-null element of the spelled out constituent/SPELLEE (68: 8-12). Schematically the SPELLEE is the complement of the head of a phase, and is a derived stress domain. What determines its status as 'the highest' rests on two conditions, namely; dominance and c-command. $\mathrm{X}$ is the highest element in the SPELLEE iff $\mathrm{X}$ dominates $\mathrm{Y}$ so that $\mathrm{X}$ is higher than $\mathrm{Y}$ in the structure; and iff $\mathrm{X}$ asymmetrically c-commands $\mathrm{Y}$ so that $\mathrm{X}$ is the highest element in the SPELLEE which asymmetrically c-commands all the elements it does not dominate. Kahnemuyipour has in mind both SOV and SVO sentences to derive sentential stress on the expected location, the object. In light of Kayne's (1994) antisymmetric theory of syntax, both SVO and SOV languages start off as SOV, where movement of the verb is assumed to derive SVO from SOV (but not in SOV). Assumed here is a split verbal structure: a lexical head $\mathrm{V}$ and a functional head $\mathrm{v}$ (phase head). For case assignment, the object moves out of VP and will end up as the specifier of the AspP.

(1)

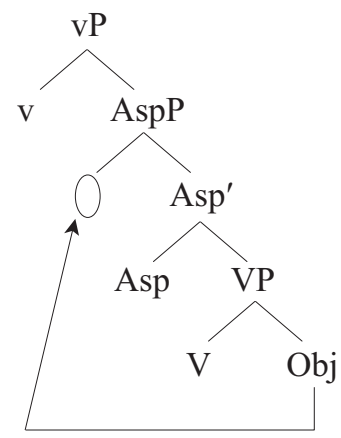

The word order issue for SVO languages arises by assuming the movement of the object to AspP. Only in SVO languages does the verb move overtly to the $\mathrm{v}$ head, whereas in SOV languages, the verb does not undergo overt movement to the specifier position of the vP, resulting in pre-verbal objects.

Kahnemuyipour introduces some Persian data to illustrate the location of stress in an SOV sentence. The highest element in the SPELLEE (stress domain) receives stress, which here corresponds to the highest Asp 
projection in the schema (1). Persian provides an interesting example of sentential stress from data drawn from the derivation of the durative prefix (2b). This verbal prefix occupies a separate functional head and sister of the $\mathrm{v}$ head. It is therefore the highest element in the SPELLEE and should be stressed. Manner (or measure) adverbials can also occupy this highest position. Unlike other adverbials (speaker oriented adverbs), in Persian these elements are inside SPELLEE (2d). In SPELLEE, the manner adverbials are merged below vP (stressed elements are underlined).

(2)
a. Ali [AspP xord].
Ali ate
'Ali ate'
b. Ali [AspP mi-xord]
Ali Dur-ate
'Ali would eat/was eating.'
c. Ali [AspP qazaa xord].
Ali food ate
'Ali ate food.'
d. Ali [AspP xub qazaa xord].
Ali well food ate
'Ali ate well.'

The verbal prefix constitutes a separate morphosyntactic word: in (2a), the verb is the highest element, but in (2b) the verbal prefix is highest element. In an SOV sentence with a non-specific object (2c), the object is the highest element in that stress domain as is shown above. Meanwhile in (2d), the stress falls on the manner adverbial, the adverbial being the highest element in the stress domain, unlike in English. Whether a language includes these adverbials in the stress domain is subject to parametric variation: Persian and Eastern Armenian have this property, while English does not. Supporting evidence for this adverbial parameter setting comes from the difference witnessed in VP fronting. The manner adverbs can be left behind in English VP-fronting, whereas the manner adverbs in Persian are obligatorily pied-piped.

In line with Chomsky $(2000,2001)$, CPs and transitive vPs form phasal boundaries, which means passive and unaccusative verb phrases do not constitute phases. In light of this condition, Kahnemuyipour proposes SPELLEE at the phasal boundary to yield sentential stress on the subject of DP: the first phrasal head of such a sentence will be $\mathrm{C}$, whose complement (SPELLEE) is TP. The highest element of this TP would be a subject in the DP in question. 
(3) Passives and unaccusative: $\underline{D P}_{\text {Subj }} \mathrm{V}$

Context: What happened?

a. My bike was stolen.

b. A boy disappeared.

c. The mail arrived.

Kahnemuyipour's analysis, unlike other syntactic approaches to sentential stress, correctly predicts the location of subsidiary stresses within the simple transitive sentence as well as complex structures. Note that the rule introduced above implies that phase operations are iterative. For every SPELLEE, the highest phonologically non-null element will be stressed and the innermost SPELLEE will receive primary stress. Outer phases contribute to subsidiary stresses.

(4) a. John saw Mary.
b. $\left[\mathrm{CP} \frac{\text { John }}{2}\left[\mathrm{vP}\right.\right.$ told $\frac{\text { Maryam }}{2}\left[\mathrm{CP}\right.$ that $\frac{\text { Jane }}{2}\left[\mathrm{vP}\right.$ saw $\left.\left.\frac{\text { Bill }]]}{1}\right]\right]$

The numbers beneath the underlined words show where the sentential stresses fall. Secondary stress is assigned on the subject in a simple transitive sentence (4a). Firstly, the object receives the stress in the vP phase, and then in the CP phase, outer SPELLEE, the subject receives the secondary stress, as shown in (5).

(5)

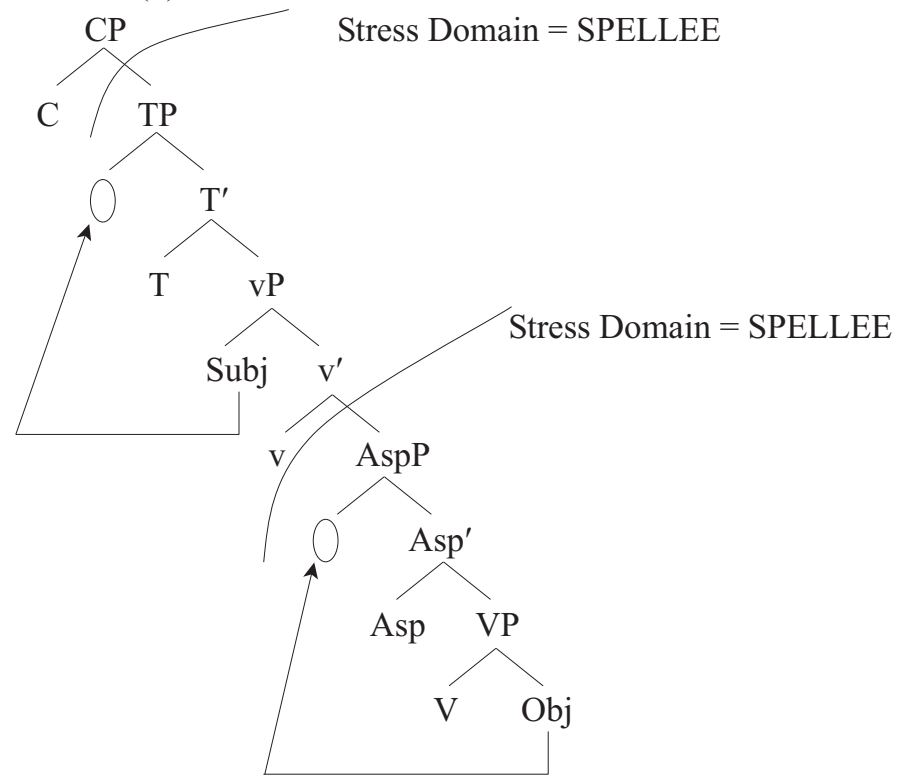


This iterativity also allows other elements to receive some level of stress in a more complex sentence as in (4b).

\section{Incorporating Information Structure}

So far, informationally neutral sentences have been analyzed in this monograph, and in Chapter 5, the discussion extends to the interaction between the information structure and sentential structure. The Focus Stress Rule (FS) is at work in languages where prosody reflects the focus mark: at the phase HP, it marks a focused sub-constituent $\mathrm{C}$ for focus stress. Independently from each other, this FSR and the Sentence Stress Rule (SS) are applied, and they interact with each other at the final stage of derivation. If there is no focus in out-of-blue contexts, FSR simply does not apply. As Kahnemuyipour demonstrates, the simple transitive sentence in (6) with focus on the subject illustrates this interaction of the two Rules.

(6) [F John] kissed Mary.

SS assigns the primary stress on Mary, the object at vP phase. FS marks John, the subject at the CP, at the same time SS independently marks John, assigning secondary stress. At the phonetic realization where both rules apply, FS gives more prominence to the element. Thus the primary stress goes to John, and the secondary to Mary.

(7) $\frac{\text { John }}{\text { FS, } \mathrm{SS}_{2}} \quad$ kissed $\frac{\text { Mary }}{\mathrm{SS}_{1}} \rightarrow \frac{\text { John kissed Mary }}{1}$

\section{Cross-linguistic Implications of the Monograph}

I would like to bring up another SOV language, Japanese, to show some of the implications of the ideas in this monograph for other languages. Kahnemuyipour follows Chomsky $(2000,2001)$ in assuming that only CPs and transitive vPs constitute phases, to account for a stress ending up on a subject in a passive/unaccusative sentence unlike the case in (2a) where the verb is the highest element of SPELLEE. Sentential accents in Japanese subject-predicate sentences rest invariably on the subject regardless of the predicate type. This suggests that none of the types of Japanese verb phrases are taken to induce phasal boundaries, or that Japanese nominatives are within the outer SPELLEE.

The way phonology interacts with syntactic structure in Japanese is intricate, and as for sentential accents, phonology applies only at the surface structure (Yoshida (1995)). This corresponds to accent assignment, in terms 
of the Minimalist approach, applying only at one of the interface levels, PF, contrastingly with word-stress that is often lexically marked. Both Japanese and Persian, as SOV languages follow similar accent assignment patterns: as long as the sentence involved takes a transitive verb, the head of SPELLEE is assigned an accent also in Japanese. Since the verb does not overtly move to the specifier position of the $\mathrm{vP}$ (thus resulting in pre-verbal objects) (see section 4), the object retains its status as the highest element in the SPELLEE to receive the sentential accent. In Japanese, unlike Persian, the subject always wins the sentential accent in the subject-verb sentence regardless of types of verbs, unaccusative or unergative. In Persian, when the verb is unaccusative, the sentential stress accent falls onto the subject (8a), otherwise the verb as the highest element of SPELLEE (8b):

$\begin{array}{rrr}\text { (8) a. } & \frac{\text { Ali }}{\text { Ali }} \text { came } & \text { 'Ali came.' } \\ \text { b. } & \text { Ali } & \text { xord. } \\ & \text { Ali } & \text { ate }\end{array}$

However in Japanese, with all the predicate types, including passive and/or causative constructions with the relevant suffix(es), the accent is assigned on the subject in focus neutral contexts (9). Accent in Japanese is phonetically interpreted as pitch accent while in stress accent languages it is interpreted as stress (Yoshida (1995)). To demonstrate which phrase will win the accent, both phrases chosen are accented in the sample sentences below in (9).
a. joN-ga kita.
(unaccusative)
John-Nom come-Past
'John came.'
b. joN-ga hashitta. (unergative)
John-Nom run-Past
'John ran.'
c. joN-ga tabesaserareta. (causative/passive)
John-Nom eat-Caus-Pass-Past
'John was made to eat.'

This implication for Japanese that verb phrases do not involve phasal boundaries or that nominatives are to be placed in $\mathrm{CP}$ has yet to be tested. This is to suggest that there are more interesting issues waiting to be solved, especially in exploring varieties like Japanese within SOV language groups to which Persian belongs. 


\section{Concluding Remarks}

This monograph explores the nature of sentential stress mainly in Persian, presenting an elegant account for both focus-neutral and non-neutral utterances. The analysis based on the notion of phases and multiple spell-out offers an effective and innovative way to account for the longstanding issue of sentential stress assignment with many interesting implications. I'd like to recommend this monograph to all those interested in syntax, phonology, and cross-linguistic typology.

\section{REFERENCES}

Boeckx, Cedric and Kleanthes K. Grohmann (2007) "Putting Phases in Perspective," Syntax 10, 204-222.

Chomsky, Noam (1995) The Minimalist Program, MIT Press, Cambridge, MA.

Chomsky, Noam (2000) "Minimalist Inquiries: The Framework," Step by Step: Essays on Minimalist Syntax in Honor of Howard Lasnik, ed. by Roger Martin, David Michaels and Juan Uriagereka, 89-155, MIT Press, Cambridge, MA.

Chomsky, Noam (2001) "Derivation by Phase," Ken Hale: A Life in Language, ed. by Michael Kenstowicz, 1-52, MIT Press, Cambridge, MA.

Cinque, Guglielmo (1993) "A Null Theory of Phrase and Compound Stress," Linguistic Inquiry 24, 239-297.

Cinque, Guglielmo (1999) Adverbs and Functional Heads: A Cross-linguistic Perspective, Oxford University Press, New York.

Kayne, Richard S. (1994) The Antisymmetry of Syntax, MIT Press, Cambridge, MA.

Legate, Julie Anne (2003) "Some Interface Properties of the Phase," Linguistic Inquiry 34, 506-516.

Yoshida, Yuko (1995) On Pitch Accent Phenomena in Standard Japanese, Doctoral dissertation, School of Oriental and African Studies, University of London. [Published by Holland Academic Graphics, The Hague (1999)]

Zubizarreta, Maria Luisa (1998) Prosody, Focus, and Word Order, MIT Press, Cambridge, MA.

[received December 20 2010, revised and accepted June 28 2011]

Faculty of Global Communications

Doshisha University

Kyo-Tanabe City 610-0394

e-mail: yuyoshid@mail.doshisha.ac.jp 